\title{
OS FUNDAMENTOS DA RESPONSABILIDADE CIVIL DO ESTADO
}

\begin{abstract}
ALEXANDRE SANTOS DE ARAGÃo*
I - Introdução. II - Influências da evolução da responsabilidade no direito civil na responsabilidade do estado. III - O fundamento da igualdade na divisão das cargas sociais. IV - Pluralidade de fundamentos da responsabilidade do estado. $V$ - Conclusão. VI - Bibliografia
\end{abstract}

\section{$I$ - Introdução}

A questão dos fundamentos da responsabilidade civil do Estado' no Direito Brasileiro é dos temas que mais está a merecer uma reflexão por parte da doutrina nacional, acostumada que está a, no trato do tema, apenas reafirmar a idéia de que o Estado é objetivamente responsável em razão do princípio da solidariedade e igualdade, pelo qual as pessoas não podem ser individual e especialmente oneradas em razão do bem comum.

Essa postura afigura-se um tanto quanto simplista se verificarmos as grandes discussões existentes no Direito Comparado, inclusive em países que adotam o sistema da responsabilidade objetiva do Estado, quanto aos fundamentos da responsabilidade civil estatal, matéria que, além da evidente importância teórica, é de grande relevância prática, uma vez que é justamente o fundamento que baliza e inspira a interpretação das diversas modalidades de responsabilização patrimonial do Estado (omissiva e comissiva, com e sem culpa ou ilicitude etc.).

* Professor das Pós-graduaçōes em Direito do Estado da Universidade do Estado do Rio de Janeiro - UERJ e em Direito da Administração Pública da Universidade Federal Fluminense - UFF. Professor do Mestrado cm Regulação e Concorrência da Universidade Candido Mendes. Procurador do Estado e Advogado no Rio de Janeiro (alexaragao@zipmail.com.br).

1 Nem sempre que o Estado paga indenizaçōes o fa\% com base $\mathrm{em}$ sua responsabilidade civil. Há certos casos em que o ordenamento jurídico regula o sacrifício de direito individual em prol do interesse público, obrigando o Estado a pagar determinada indenização (ex.: desapropriação).Fm casos tais, não há responsabilidade civil, mas, sim, sacrifício de direito legalmente autorizado.

R. Dir. Adm.,

Rio de Janeiro, 236: 263-273,

Abr./Jun. 2004 
Podemos constatar que, de fato, a responsabilidade do Estado no Direito Brasileiro é uma das que mais confere direitos aos administrados que sofrem danos patrimoniais ou morais, ${ }^{2}$ encontrando paralelo em poucos outros países. ${ }^{3}$

Para alguns, esta super-proteção pode ser vista como um avanço do Direito brasileiro em relação ao de outros países, mas outros podem vê-la como, na verdade, um nivel de preocupação não muito elevado com o Erário da coletividade, como uma emanação da consciência brasileira de ver o Estado menos como uma res publica e mais como uma res nullius.

Veja-se, por exemplo, em apertada síntese do exposto por Odete MEDAUAR, ${ }^{4}$ que em França a regra é a responsabilidade do Estado por culpa, ainda que às vezes presumida em bens ou atividades de risco; na Itália a responsabilidade do Estado é, em princípio, relacionada com a do servidor, havendo inclusive controvérsias quanto à possibilidade de se acionar diretamente o Estado; a Espanha é um dos poucos países europeus que, pela interpretação dada à sua Constituição e leis pertinentes, consagram uma responsabilidade objetiva e geral semelhante à brasileira; na Alema-

2 Abordando a história da responsabilidade objetiva do Estado no Direito Brasileiro, Yussef Said CAHALI (CAHALI, Yussef Said. Responsabilidade Civil do Estado, Ed. Malheiros, 1995, pp. 28 a 43) lembra as controvérsias hermenêuticas que foram verificadas em relação ao Código Civil de 1916, com a opinião, que acabou por não prevalecer, pela qual o Código já teria adotado a responsabilidade objetiva em virtude da teoria do risco já em voga na França, opiniāo que, contudo, não se compaginava com o contexto liberal-individualista que marcava este Código. $O$ autor destaca a Constituição de 1946 como a inauguradora no Direito Brasileiro da responsabilidade objetiva do Estado, uma vez que, ao distinguir a responsabilidade do Estado e a responsabilidade do servidor. se referiu à culpa apenas em relação a esta. Esta concepção reflete a evolução da inovação da teoria publicista, que, à diferença da responsabilidade solidária do patrão, ou do comitente, fazia com que a responsabilidade do serviço público se constitua numa responsabilidade primária, vinculando o patrimônio da Administração direta e imediatamente; desaparece a dualidade de pessuas, absorvida a pessoa física do funcionário pelo ente administrativo: a falta do serviço público não é mais necessariamente ligada à idéia de falta de um agente determinado. bastando, para a responsabilidade, um mau funcionamento geral, anônimo, uma falha do serviço, a qual o dano possa ser imputado. As discussões, então, passaram a versar sobre a amplitude desta responsabilidade objetiva, tendo sido bastante divulgada a visão de Hely Lopes MEIRELLES, segundo o qual a responsabilidade objetiva do Estado se funda em uma subespécie de risco integral, o risco adıninistrativo, pelo qual não seriam todos os danos sofridos por terceiros que ensejaria a responsabilidade do Estado, mas apenus aqueles com nexo de causalidade com a atuação estatal, nexo de causalidade este excluído total ou parcialmente quando o dano fosse causado por caso fortuito, força maior, culpa da própria vítima ou de terceiros. A maioria da doutrina atual, contudo, relativiza esta posição, relegando-a a uma distinção apenas de nomenclatura, uma vez que, mesmo aqueles que entendem tratar-se de uma responsabilidade objetiva por risco integral a adotada no Direito Brasileiro, admitem as excludentes acima mencionadas. A chave da questão estaria, então, não na admissão de excludentes de responsabilidade, ou na adoção da Teoria do Risco Administrativo ou do Risco Integral, mas sim no relevo a ser dado ao nexo de causalidade com a ação do Estado, sem o qual não que se falar em responsabilidade do Estado.

3 MEDAUAR, Odete. A Responsabilidade Pública em alguns Ordenamentos Europeus, 2003, mimeo.

4 MEDAUAR, Odete. A Responsabilidade Pública em alguns Ordenamentos Europeus, 2003, mimeo. 
nha, fora dos casos de sacrifício legítimo que implique em indenização (ex.. desapropriação) e responsabilidades decorrentes de outras previsões normativas, o Estado só é responsável pelos ilícitos praticados por seus servidores, "o que, em geral, significa a responsabilidade dos Entes públicos, que a assumem"; e na Inglaterra a Coroa só é responsável se o servidor, pessoalmente. também o for. ${ }^{5}$

Visamos, nessa senda, menos a esgotar o tema dos fundamentos da responsabilidade do Estado do que a suscitar a discussão que, ao nosso ver, deve ser travada na matéria, mais complexa, como veremos, do que a monocórdica afirmação da igualdade na repartição dos ônus sociais como o fundamento da responsabilidade objetiva do Estado.

\section{II - Influências da evolução da responsabilidade no direito civil na responsabilidade do estado}

Para Guido GRECO ${ }^{6}$ a responsabilidade civil do Estado traz sérios problemas hermenêuticos para o intérprete porque demanda a adaptação dos paradigmas civilistas originários às peculiaridades do Estado e das funções públicas.

Isto se explica, segundo o autor, "pela circunstância de que a responsabilidade da Administração Pública é em última análise sustentada pelos cidadãos - através do sistema fiscal - que arcam com os ônus. Desta forma, a questão de fundo que habitualmente envolve a responsabilidade civil (direcionada a individuar a sua medida e, assim, o limite além do qual se deve atribuir os custos de uma ação a quem provocou o dano, e não a quem o sofreu) tem o risco de na nossa seara possuir conotação de todo diversa: trata-se, com efeito, de estabelecer até quando o sacrifício sofrido por um sujeito em virtude de uma atividade antijurídica da Administração Pública deve permanecer consigo mesmo, e quando, ao revés, gravar a Administração e, assim, em última análise, a coletividade como um todo".?

5 Tratando comparativamente dos Direitos Inglês. Alemão e Suiço, Jesús LEGUINA, resume: "Tal es, en resumen, el marco general dentro del cual se desenvuelve hoy la aplicación del principio de responsabilidad administrativa en los tres Derechos nacionales estudiados: ilegalidad. culpabilidad y cobertura de conductas individuales son los tres pilares básicos que sustentan el edificio en el que los particulares pueden hallar reparación. Las lineas maestras del instituto siguen siendo, pues, virtualmente idénticas a las que regian en la elapa inmediatamente anterior: antes respondia sólo el funcionario frente a la victima; ahora responde la Administración de la que aquél forma parte, pero lo hace en base a idéntico fundamento y por las mismas razonc's por las que deberia responder el propio funcionario causante del daño. Se trata, en definitiva, de una responsabilidad indirecta o derivada del hecho de un tercero, que gira en torno al concepto de acción u omisión ilícita alzaprimando el criterio de imputación por culpa, y cuya principal virtud consiste, en fin. en proteger a las víctimas frente al riesgo de insolvencia de los autores materiales de los daños" (LEGUINA, Jesús. El fundamento de la responsabilidad de la Administración. in Revista Española de Derecho Administrativo - REDA, versĩo CD-ROM).

6 GRECO, Guido. Diritto Amministrativo, coord. MAZZAROLI, L., PERICU, G., ROMANO, ROVERSI MONACO. F.A.. SCOCA, F.G.. 2a edição, Monduzzi Editore, 1998, pp. 1.671 a 1.673. 7 GRECO, Guido. Diritto Amministrativo, coord. MAZZAROLI, L., PERICU, G., ROMANO, ROVERSI MONACO, F.A., SCOCA, F.G., 2a edição, Monduzzi Editore, 1998, p. 1.673. 
Concordamos apenas em parte com o autor italiano, com cujas afïrmações só podemos anuir de forma integral se considerada a conformação tradicional, liberaloitocentista, da responsabilidade no Direito Civil, já que, conforme entendemos, o caráter objetivo da responsabilidade do Estado e a adoção da Teoria do Risco na sua seara, ao contrário de constituir uma criação originária do Direito Administrativo, cuja construção científica ainda não se encontrava em tal estágio de amadurecimento e autonomia científica, adveio da extensão à Administração Pública de postulados criados no âmbito do próprio Direito Civil, em razão da evolução das relações privadas, que, por razões de eqüidade e de segurança jurídica, exigiam mais do que a culpa ou a ilicitude como o único fundamento da obrigação de ressarcir danos.

Marcel SOUSSE ${ }^{8}$ observa que "no fim do século XIX, alguns autores, particularmente atentos à evolução econômica e social, lançam a idéia de uma inadaptação da culpa a essa evolução. A culpa. até então incontestável, ter-se-ia tornado incapaz de propiciar a indenização das vítimas de acidentes de trabalho, cada vez mais numerosas. Estes, com efeito, geralmente não têm a possibilidade de provar a negligência ou a imprudência do patrão, e o nexo de causalidade entre a culpa e o dano. O Parlamento francês foi levado a tratar desse problema, e as discussões, que se prolongaram por dezoito anos, puseram na ordem do dia as idéias de risco industrial' e de 'risco profissional"."

Expandindo estas novas concepções do Direito Civil, dos acidentes do trabalho para as relações individuais em geral, "L. JOSSERAND, que seria considerado mais tarde como co-fundador da Teoria do Risco, desenvolve argumentos idênticos, considerando que o fundamento da obrigação de reparar esses danos deve ser encontrado não mais na culpa, mas, em certas situações, no risco. Assim, iria nascer a idéia de uma responsabilidade objetiva", ${ }^{10}$ que, partindo dos acidentes de trabalho, foi, desde 1896, estendida a uma série de danos decorrentes das novas atividades técnicas que, com a evolução da indústria e da tecnologia, passaram a ser exercidas com inevitáveis chances de causarem acidentes, por mais que seus titulares tomassem todas as cautelas possíveis.

Foram essas necessidades da época que levaram à criação da Teoria do Risco no Direito Civil, que, por semelhança de razões - diante de uma Administração Pública que cada vez mais ampliava horizontal e verticalmente as suas modalidades e áreas de intervenção na vida social e econômica (nacionalizações, fomento, pla-

8 SOUSSE, Marcel. La Notion de Réparation de Dommages en Droit Administratif Français, LGDJ, Paris, 1994, p. 110.

9 Uma tentativa de compor essas necessidades econômicas e sociais com a idéia clássica de culpa foi a da culpa presumida, mas na verdade tratava-se de uma tentativa de manter sempre a idéia de responsabilidade dentro dos limites da culpa, quando ela eclodiria ainda que se comprovasse inexistir qualquer culpa. "Quando nos colocamos esta questão, geralmente percebemos que não é de presunção de culpa que devemos falar: a culpa não está presumida, ela é falsa”" (EISENMANN, Charles. Cours de Droit Administratif, Tome II, LGDJ, Paris, 1983, p. 867).

10 SOUSSE. Marcel. La Notion de Réparation de Donmages en Droit Administratif Français, LGDJ, Paris, 1994, p. 110. 
nejamento, sociedades de economia mista e empresas públicas, forte regulação das atividades privadas etc.) - foi estendida ao Direito Administrativo.

Como afirma Jesús LEGUINA," a Administração Pública, enquanto gestora institucional dos interesses coletivos e mediadora dos conflitos de interesses privados, assumiu o papel de protagonista insubstituível na direção de todas as atividades econômicas e sociais, sem que exista hoje parcela alguma da sociedade civil em que, de alguma forma, não esteja presente a sua ação. Nos encontramos, pois, ante uma Administração pública quantitativa e qualitativamente distinta da que era própria de um modelo de relações econômicas de corte liberal clássico. A Administração deve, com efeito, planificar, dirigir, ordenar, multiplicar sua ação prestacional, promovendo condições de existência dignas para todos os sectores sociais.

Nesse sentido, prossegue o autor ibérico, a responsabilidade patrimonial não é, nem deve ser, um freio que dificulte o paralise as funciones de intervenção administrativa no sentido apontado, mas deve significar o reconhecimento de que as seqüelas negativas de tais funções não devem gravitar sobre patrimônios ou interesses privados isolados afetados, mas sobre toda a comunidade a que a Administração serve. Se os benefícios das funções administrativas alcançam potencialmente a todos, também os prejuízos devem ser repartidos entre todos.

O liame entre a evolução do Direito Civil do início do século passado e a adoção da Teoria do Risco pelo Direito Administrativo na mesma época fica muito claro quando verificamos as primeiras lições dos administrativistas clássicos que. pioneiramente, sustentaram a responsabilidade objetiva do Estado pelos danos por ele causados aos particulares.

Maurice HAURIOU, ${ }^{12}$ por exemplo, afirma ser evidente que a grande empresa é incompatível com a teoria da culpa, que repousa sobre a presunção do pater

11 LEGUINA, Jesús. El fundamento de la responsabilidad de la Administración, in Revista Española de Derecho Administrativo - REDA, versão CD-ROM. A evolução da responsabilidade administrativa se dá por um movimento progressivo e linear cada vez mais protetivo das vítimas, o que é explicado pela importância que as atividades públicas têm ná nossa sociedade, pela grande necessidade contemporânea de que todos os danos sejam ressarcidos e pelos progressos do Estado de Direito. Para Michel PAILLET, "o refluxo da soberania e a promoção histórica da noção de serviço público foram ampliadas pelo progresso da idéia de solidariedade social para reduzir a quase nada a zona de irresponsabilidade dos poderes públicos (puissance publique), que, em razão da multiplicação dos serviços públicos, passaram a ter um papel cada vez maior no campo social. A consciência jurídica no Estado liberal (État-gendarme) se acomodou com uma responsabilidade administrativa bastante limitada, que se demonstrou incompatível com o advento do Estado-providência, com a multiplicação das atividades públicas e, conseqüentemente, dos danos por elas provocados. A atenuação das condições para desencadear a responsabilidade administrativa respondeu a estas expectativas, e a sua diversificação permitiu a modulação dos seus efeitos para que tivesse uma pluralidade de funções: sanção, seguro, preço a ser pago e garantia social (PAILLET, Michel. La Responsabilité Administrative. Paris, Dalloz, 1996, p. 9).

12 HAURIOU, Maurice. Note sous C.E., 13 janvier 1899, Lpreur. S., 1900, III, pp. 1 a 3 . Não se pode, no entanto, omitir a mudança de opinião de Hauriou, que, mais tarde, manifestou seus receios com os riscos orçaınentário-financeiros que uma dimensão expansiva da Teoria do Risco poderia acarretar para os cofres públicos (in Note sous C.E., 28 mars 19/9, Regnault-Desroziers, S., 1918-19/9. (II, p. 25). 
familiae, ou seja, do homem que toma conta com diligência de todos os detalhes de uma exploração sua. A culpa. então, não poderia mais ser vista como a causa do prejuízo, "devendo o prejuízo ser considerado em si mesmo como um acidente, e a reparação do prejuízo como um encargo da empresa". Sendo assim, à Administração Pública, vista como "uma enorme empresa, a mais importante de todas", não pode ser aplicada a Teoria da Culpa, devendo ficar próxima, talvez, da idéia de seguro social, mesmo que a ele cheguemos através do risco industrial.

Léon DUGUIT. ${ }^{13}$ por sua vez, considerava "que o domínio da responsabilidade subjetiva se restringe cada vez mais, a ponto de o princípio da imputabilidade não poder mais ser aplicado quando, ao invés de tratar-se de relações entre indivíduos, estivermos diante de relações entre grupos entre si, ou entre grupos e indivíduos". Não seria mais uma questão de imputabilidade, mas sim de risco.

\section{III - O fundamento da igualdade na divisão das cargas sociais}

Vemos, portanto, que a invocação da igualdade na repartição dos encargos sociais constituiu uma explicação dos administrativistas para a aplicação da Teoria do Risco à Administração Pública. ao passo que, no Direito Civil, à época denominado "Direito Comum", já se propugnava a aplicação desta Teoria a todos os riscos causados pelo desempenho das atividades das grandes organizações, entre as quais a Administração Pública, por óbvio, se encontrava: "Até meados do século XIX, a maior parte dos danos advinha de uma falta que comportava uma liberdade de escolha. As falhas eram mais ou menos deliberadas. Com o advento da maquinização, os danos acidentais se multiplicam, passando a ser primordiais. Como a sua terminologia indica, os danos acidentais são em larga margem decorrentes do acaso. Ainda que resultem de falhas humanas, estas são estatisticamente inevitáveis". ${ }^{4}$

A doutrina clássica (aproximadamente do início do século passado até o final da Segunda Grande Guerra) era unânime na adoção do fundamento da igualdade dos indivíduos perante as cargas públicas: "as coisas se passariam como se o Estado gerisse, na sua qualidade de pessoa jurídica, um seguro mútuo contratado entre os administrados contra os riscos dos acidentes administrativos. A idéia de tal seguro advém logicamente do princípio da igualdade perante a lei e os encargos públicos". ${ }^{15}$

Após o Pós-guerra, essa doutrina passou, contudo, a sofrer graves críticas. Uma das mais contundentes e difundidas foi a de Charles EISENMANN, que critica a generalização do argumento pelo qual o fundamento da responsabilidade do Estado seria a equânime repartição de encargos em virtude do princípio da igualdade e da

13 DUGUIT, Léon. Les Transformations Génerales du Droit Privé depuis le Code Napoléon. Alcan, Paris, 1912, pp. 137 e segs.

14 TUNC. A., apud SOUSSE, Marcel. La Notion de Réparation de Dommages en Droit Administratif Français. LGDJ, Paris, 1994, p. 115.

15 HAURIOU, Maurice. Les Actions en Indemnité contre l'État pour préjudices causés dans l'Administration Publique, Revue de Droit Public. 1896, p. 51 e segs. 
solidariedade social, que seria compatível apenas com os encargos específicos sofridos para satisfazer um interesse público expresso (ex., em razão de uma obra pública, a recusa de obedecer a uma ordem judicial por razões de ordem pública), não em razão de ilegalidades ou acidentes (ex., como alegar que a sociedade se beneficiou com uma tortura realizada pelos agentes estatais, que, naturalmente, deve acarretar a indenização da vítima). Apenas nos primeiros casos poderíamos dizer que a coletividade é beneficiária das atividades que ocasionaram danos necessários e conscientes a um particular específico, que, portanto, foi desigualmente onerado para propiciar este benefício. ${ }^{16}$

Para o autor apenas nestes casos temos um fundamento de responsabilidade específico do Direito Administrativo. Nos demais, certamente não há responsabilidade por falta, mas sim por uma "correlação entre vantagens e encargos" (ex.; se aufere os benefícios de uma atividade de risco deve arcar com os ônus que dela decorram por acidente ou por culpa dos seus empregados), originária e existente no Direito Civil, mas apenas em menor escala. ${ }^{17}$

\section{IV - Pluralidade de fundamentos da responsabilidade do estado}

Do exposto já ressai ser difícil compreender todas as nuances dos eventos ensejadores da responsabilidade do Estado sob o único fundamento da igualdade na repartição dos encargos sociais.

Além de uma análise da responsabilidade do Estado não poder ser efetuada sem considerar as numerosas posições que refutam de forma absoluta esse fundamento, devemos, sobretudo, ter em mente que, muitos dos que ainda o acolhem, em sua maioria não o fazem de forma indiscriminada para todas as espécies de responsabilidade pública.

Nem se poderia afirmar que a nossa Constituição teria adotado esse fundamento ao constitucionalizar a responsabilidade objetiva do Estado no art. $37, \S 6^{\circ}$, já que é tranqüilo na doutrina e na jurisprudência que, pelo menos no caso dos danos por omissão administrativa, estaríamos diante de um caso de responsabilidade por falha da Administração Pública.

Igualmente, diante de responsabilidade por atos ilícitos, a obrigação do Estado só exsurge se comprovada a ilicitude (ex., ninguém pode pedir indenização em razão dos prejuízos causados por uma autuação fiscal legítima, podendo fazê-lo apenas se for comprovada a sua ilicitude).

Francis-Paul BÉNOIT distingue o fundamento da responsabilidade da Administração Pública conforme se trate, de usuário do serviço público que causou o dano, ou de terceiro. Em relação àqueles o seu fundamento é o direito que possuem ao bom funcionamento do serviço; ao passo que para os terceiros ao serviço público

16 EISENMANN, Charles. Cours de Droit Administratif, Tome II, LGDJ, Paris, 1983, pp. 870 a 872.

17 EISENMANN, Charles. Cours de Droit Administratif, Tome II, LGDJ, Paris, 1983, p. 873. 
o fundamento seria mais genérico, consubstanciado no direito a não sofrer nenhum dano anormal por fatos produzidos pela Administração Pública. ${ }^{18}$

Para o autor, o fundamento da responsabilidade da Administração Pública não é a igualdade. Não que ela não seja, aliás, como todos os outros institutos jurídicos devem ser, comandada pela idéia de igualdade, e é bom que seja assim. Mas pensar que a igualdade é o fundamento específico da responsabilidade, "é misturar o problema jurídico do fundamento das instituições e o problema político da apreciação do seu valor". 19

Alguns autores sustentaram que a Teoria do Risco, outros que a Teoria dos Danos Anormais, deveriam ser consideradas como os fundamentos autônomos da responsabilidade do Estado, não podendo ser considerados como meras explicitações do fundamento da igualdade perante os encargos sociais. ${ }^{20}$

Outra forte corrente considera como fundamento da responsabilidade do Estado a garantia social inerente ao Estado Democrático de Direito, por forças do qual as pessoas não podem ter a sua esfera jurídica coarctada pela coletividade, ainda que esta esteja atuando licitamente ou até mesmo em razão de dever legal.

Por esta posição, aplicável, sobretudo, nos casos de responsabilidade do Estado por atos lícitos. não se trata propriamente de tornar indiferente a ilicitude, mas sim de deslocar o foco da sua análise do comportamento estatal para a esfera jurídica do cidadão.

Assim, Jesús LEGUINA ${ }^{21}$, tratando do Direito da Espanha, que, como o Brasil, também está entre os poucos países que adotam a responsabilidade objetiva do Estado, observa que o primeiro dado, portanto, que há de se considerar quanto à responsabilidade administrativa, aquele que a fundamenta, organiza e dá sentido, é o dado objetivo da lesão antijurídica, entendida como o dano que um particular sofre em seus bens ou direitos sem que tenha a obrigação legal de suportá-los. A ilicitude do dano, que postula a sua imputação à Administração autora do mesmo, não depende, pois, de uma prévia ilicitude da ação ou omissão de algum órgão administrativo, mas se configura objetivamente na incidência do fato danoso sobre ou patrimônio do lesado em todos os casos em que não haja fundamento legal que, de modo expresso e compatível com a Constituição - acresceríamos - obrigue este a suportar o detrimento patrimonial. A ilicitude do fato lesivo se mede, então, pelos efeitos negativos injustificados sobre o patrimônio do particular, não na valoração negativa da ação que o provoca. Do que se infere que uma ação ou omissão administrativa legítima e sem culpa não é insuscetível, apenas por isso, de causar uma lesão ilícita e, por essa razão, ressarcível.

18 BÉNOIT, Francis-Paul. Le Droit Administratif Français, Ed. Dalloz, Paris, 1968, p. 691.

19 BÉNOIT, Francis-Paul. Le Droit Administratif Français, Ed. Dalloz, Paris, 1968, p. 693.

20 SOUSSE, Marcel. La Notion de Réparation de Dommages en Droit Administratif Français, LGDJ, Paris, 1994, pp. 125 a 128.

21 LEGUINA, Jesús. El fundamento de la responsabilidad de la Administración, in Revista Española de Derecho Administrativo - REDA, versão CD-ROM. 
Mais adiante, declara o autor "superada a clássica dicotomia entre açóes lícitas e ações ilícitas (dicotomia que, ademais, é irrelevante para o prejudicado, pois tanto faz que a sua lesão patrimonial proceda ou não de uma conduta (ulpável), consagrando em seu lugar um principio geral de garantia patrimonial dos particulares, que pode ser invocado com êxito frente a qualquer tipo de lesão antijurídica causada pelo funcionamento, tanto normal ou lícito como anormal ou ilícito, dos serviços públicos". 22

E mais, os casos como, por exemplo, os dos danos sofridos em razão de manifestações multitudinárias ou de crimes praticados por terceiros, na medida em que sequer há a intervenção causal da Administração, desbordam de certa forma do âmbito da responsabilidade patrimonial para inscreverem-se mais apropriadamente no campo da seguridade social, cumprindo, assim, um papel análogo e complementar dos seguros sociais públicos. Exemplo extremo desta modalidade de obrigação pecuniária do Estado, mais de seguridade social que de responsabilidade civil, foi a instituída pela recém editada Lei $\mathrm{n}^{\circ} 10.744$, de 09 de outubro de 2003, que, adotando a Teoria do Risco Integral, propicia à União arcar com os prejuízos que venham a ser causados por atos terroristas. ${ }^{23}$

\section{$V-$ Conclusão}

O tema dos fundamentos da responsabilidade civil do Estado merece ser mais aprofundado por nossa doutrina, uma vez que a idéia da igualdade na repartição dos encargos sociais como o seu único fundamento leva a uma expansão inadvertida dos permissivos da responsabilização estatal, quando as diversas circunstâncias aptas a

22 LEGUINA, Jesús. El fundamento de la responsabilidad de la Administración. in Revista Española de Derecho Administrativo - REDA, versão CD-ROM, grifamos. "De este modo, la responsabilidad de los entes públicos ha de ser calificada en el De recho español como una responsabilidad directa y principal, puesto que cubre no sólo los daños impuables a las conducıas individuales de agentes públicos concretos, sino también las lesiones ocasionadas por el funcionamiento impersonal, institucional o anónimo de la organización administrativa. Y puede ser concepuada también como una responsabilidad objetiva, en la medida en que la culpa individual o institucional ha dejado de ser el fundamento mismo del deber de reparación para ceder ese puesto al elemento objetivo de la antijuridicidad del daño sufrido por un tercero. La culpa es ahora en el Derecho español un simple criterio de imputación de daños que, junto a otros criterios (tales como la ilegalidad del acto, el riesgo creado en peligro de terceros o, según algunos autores, el enriquecimiento indebido), permite trasladar los efectos negativos del hecho donoso desde el patrimonio de la víctima hacia el patrimonio de la Administración y, eventualmente, dirimir también el reparto de responsabilidades entre aguélla y el agente físico cuya conducta haya causado materialmente el daño" (autor e ob. cit.).

23 Art. $1^{\circ}$ Fica a União autorizada, na forma e critérios estabelecidos pelo Poder Executivo, a assumir despesas de responsabilidades civis perante terceiros na hipótese da ocorrência de danos a bens e pessoas, passageiros ou não, provocados por atentados terroristas, atos de guerra ou eventos correlatos, ocorridos no Brasil ou no exterior, contra aeronaves de matrícula brasileira operadas por empresas brasileiras de transporte aéreo público, excluidas as empresas de táxi aéreo. 
fazer esta eclodir demandam maiores cautelas e sutilezas, fazendo com que o que poderia representar um avanço da cidadania, cada vez mais garantida em face do Estado, constitua na verdade uma demonstração cultural do pouco zelo da sociedade brasileira com o espaço público.

Isto faz com que a responsabilidade da Administração Pública possa vir a ser injustificadamente ampliada, já que a sociedade muitas vezes pode não ter a exata dimensão da imputação do ônus financeiro correspondente, o que também vem acontecendo com o aumento dos custos dos serviços prestados por profissionais sujeitos legal ou jurisprudencialmente a fortes obrigações indenizatórias. ${ }^{24}$

Jaime RODRÍGUEZ-ARANA afirma "Ihe parecer que o Estado social e democrático de Direito não se compadece com esta super-blindagem, super-defesa que os funcionários públicos possuem frente aos cidadãos em decorrência do princípio da responsabilidade objetiva e universal da Administração Pública. (...) Se deve ter presente que a consequiência dos atos são da conta dos funcionários, razão pela qual de uma aplicação objetiva e global da responsabilidade administrativa não é compatível com um entendimento moderno do sentido da liberdade e da responsabilidade. (..) É por esta razão que, insisto, em um Estado social e democrático de Direito, a inclusão do funcionamento normal de serviços públicos entre os fatos que podem acarretar a responsabilidade da Administração Pública pode gerar sérios problemas interpretativos". 2.5

O autor afirma que este sistema de responsabilidade civil do Estado, concebido na década de cinqüenta, não mais se coaduna com a sociedade e com o Estado contemporâneos, "nos quais o interesse público não é mais um conceito que o funcionário monopoliza ou interpreta unilateralmente, mas sim que, como afirmara o Tribunal Constitucional já em 1984, é um conceito que se define harmonicamente através da intercomunicação entre os poderes públicos e os agentes sociais. (...) Como assinalado pelo Professor García de ENTERRÍA, (...) atualmente o interesse público reside na promoção dos direitos fundamentais". ${ }^{26}$

Esperamos, portanto, como afirmado no início deste estudo, termos, sem a pretensão de esgotar o tema, demonstrado, principalmente à luz das construções doutrinárias que têm sido elaboradas no Direito de outros países, com destaque para a Espanha, cujo sistema de responsabilidade é análogo ao nosso, que os fundamentos da responsabilidade do Estado são dotados de complexidade bem maior do que à primeira vista pode parecer.

24 SORACE, Domenico. Problemi e Prospettive delle Responsabilità Pubbliche, constante da obra coletiva Le Responsabilità Pubbliche (coord. Domenico Sorace), Ed. CEDAM, Milano, 1998, pp. XIV e XV.

25 RODRÍGUEZ-ARANA, Jaime. Nuevas Orientaciones Doctrinales sobre la Responsabilidad Patrimonial de la Administración Pública, in Scientia Iuridica, Universidade do Minho, Braga, $\mathrm{n}^{\circ}$ 293, maio/agosto, 2002, p. 272, 276 e 277.

26 RODRÍGUEZ-ARANA, Jaime. Nuevas Orientaciones Doctrinales sobre la Responsabilidad Patrimonial de la Administración Pública, in Scientia Iuridica, Universidade do Minho, Braga, $n^{\circ}$ 293, maio/agosto, 2002, p. 274. 
Essa complexidade deve ter reflexos em uma maior cautela na afïrmação da responsabilidade do Estado nos casos concretos com os quais o fundamento da igualdade perante as cargas sociais, que, como visto, não é o único fundamento da responsabilidade estatal, não seja compatível.

\section{VI-Bibliografia}

BÉNOIT, Francis-Paul. Le Droit Administratif Français, Ed. Dalloz, Paris, 1968.

CAHALI, Yussef Said. Responsabilidade Civil do Estado, Ed. Malheiros, 1995.

DUGUIT, Léon. Les Transformations Génerales du Droit Privé depuis le Code Napoléon, Alcan, Paris, 1912.

EISENMANN, Charles. Cours de Droit Administratif, Tome II, LGDJ, Paris, 1983. GRECO, Guido. Diritto Amministrativo, coord. MAZZAROLI, L., PERICU, G., ROMANO, ROVERSI MONACO, F.A., SCOCA, F.G., 2a edição, Monduzzi Editore, 1998.

HAURIOU, Maurice. Les Actions en Indemnité contre l'État pour préjiddices causés dans l'Administration Publique, Revue de Droit Public, 1896. . Note sous C.E., 13 janvier 1899, Lepreux, S., I900, III.

LEGUINA, Jesús. El fundamento de la responsabilidad de la Administración, in Revista Española de Derecho Administrativo - REDA, versão CD-ROM.

MEDAUAR, Odete. A Responsabilidade Pública em alguns Ordenamentos Europeus, 2003, mimeo.

PAILLET, Michel. La Responsabilité Administrative, Paris, Dalloz, 1996.

RODRÍGUEZ-ARANA, Jaime. Nuevas Orientaciones Doctrinales sobre la Responsabilidad Patrimonial de la Administración Pública, in Scientia Iuridica, Universidade do Minho, Braga, $n^{\circ}$ 293, maio/agosto, 2002.

SORACE, Domenico. Problemi e Prospettive delle Responsabilità Pubbliche, constante da obra coletiva Le Responsabilità Pubbliche (coord. Domenico Sorace), Ed. CEDAM, Milano, 1998.

SOUSSE, Marcel. La Notion de Réparation de Dommages en Droit Administratif Français, LGDJ, Paris, 1994.

TUNC. A., apud SOUSSE, Marcel. La Notion de Réparation de Dommages en Droit Administratif Français, LGDJ, Paris, 1994. 


\title{
Repertório de Jurisprudência Trabalhista
}

\author{
João de Lima Teixeira Filho
}

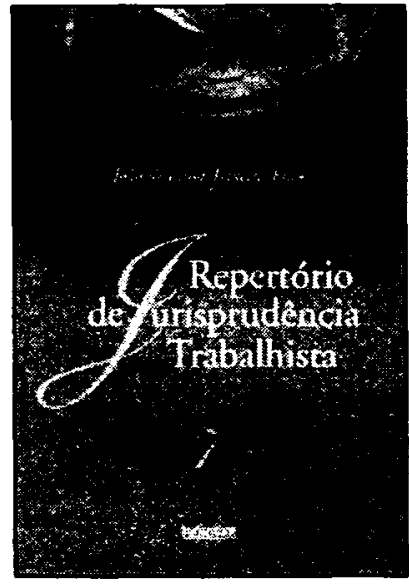

O Repertóno permanece fiel à diretriz de minimizar o tempo de consulta na busca do assunto pesquisado. Daí apresentar um índice o mais detalhado possível. Não é mera repetiçāo das Seções que compōem os Capítulos do livro. $\mathrm{O}$ índice minudencia mais ainda os assuntos e consolida num mesmo título o tema tratado, direta ou indiretamente, em mais de um setor do livro. Não há notas remissivas internas; só no índice. A consulta ao índice é, portanto, a forma mais eficaz de pesquisar acórdāos no Repertório.

Ref. 0215

Form. 16x23

Encadernado

1999

1.289 págs.

vol. 7

\section{Responsabilidade Internacional do Estado}

Celso D. de Albuquerque Mello

Este livro versa a natureza jurídica da responsabilidade, proteção diplomática, atos do Executivo, Legislativo e Judiciário, violação dos direitos humanos, contratos internacionais, reparação etc. Inúmeras questōes atuais são examinadas como a responsabilidade resultante da exploração nuclear e espaço exterior. Outro tema analisado é a discussão sobre a natureza da responsabilidade em caso de poluição.

Ref. 0085

Form. 14x21
Brochura 1995

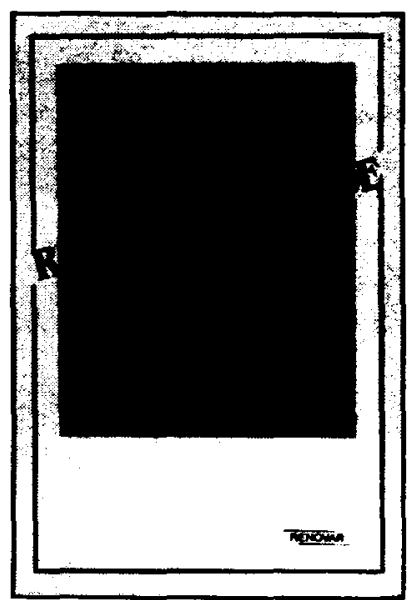

